\title{
Review of Agnes Callard, Aspiration
}

\author{
Paul Katsafanas \\ Boston University
}

Draft May 20, 2019

\section{Forthcoming in Philosophy and Phenomenological Research}

Callard's goal is to give an account of "aspiration", which she defines as "the rational process by which we work to care about (or love, or value, or desire...) something new" (4). The aspirant sees the possibility of having a new value and strives to acquire it. But there's a twist: in the cases that interest Callard, the aspirant will have only an inchoate or partial understanding of the value that she seeks to acquire (6). So the aspirant works both to acquire a new value and to come into a fuller understanding of this value.

Let's illustrate this with one of Callard's examples, to which I'll repeatedly return. Consider two students who are taking a music class. One student—let's call him Brad-merely seeks to attain a good grade in the class. If he can do that without coming to understand music's value, that's fine with him (70). The other student-let's call her Jane-also wants good grades, but she would reject any approach that resulted in good grades without also being conducive to her goal of appreciating music (70). Jane "is genuinely oriented toward the intrinsic value of music" in the sense that she aims at valuing music for its own sake (70). Nonetheless, Jane hasn't yet become a person who values music for its own sake. This shows up in two ways. First, she "is unable to articulate, to her own satisfaction, what she expects to get out of her music class" (70). She doesn't quite grasp the value of music, though she wants to. Second, her behavior differs from that of agents who do value music for its own sake. Jane may have to force herself to listen to symphonies, or promise herself chocolates if she listens for a bit longer, or engage in fantasies about what it will be like to enter a concert hall while appreciating music; but "someone who already valued music wouldn't need to motivate herself in any of these ways" (69).

In short: Jane wants to appreciate music for its own sake, but she's not there yet; and to get there, she needs external inducements. Nonetheless, Jane is different than Brad; she wants to deepen her appreciation or music and she'd reject external inducements if they weren't conducive to her goal of valuing music. So Jane is an aspirant; Brad isn't.

Callard claims that aspiration is a "distinctive form of agency." It is distinctive because:

If aspiration is to be an exercise of human agency, aspirants must be responding to practical reasons of some kind. Behavior qualifies as agency insofar as it exhibits the distinctive intelligibility of being a response to reasons... There are, however, problems in identifying the reason on which the aspirant acts. (9)

Standard accounts of rational agency are, Callard claims, unable to identify the reason on which the aspirant acts. Callard argues that in order to account for aspiration, we have to introduce a new type of reason, proleptic reasons. Proleptic reasons have "two faces: a proximate face that reflects the 
kinds of things that appeal to the person she is now and a distal one that reflects the character and motivation of the person she is trying to be" (73). So Jane has one reason, a proleptic reason, which incorporates two considerations in a non-additive way. And that's Callard's distinctive claim: in order to account for aspirational action, we need to introduce proleptic reasons.

I'm skeptical. There's no doubt whatsoever that people engage in the sorts of activities that Callard is describing: people sometimes do aim at acquiring new values. The question is whether this raises any distinctive philosophical puzzles. I'm not convinced that it does. If we make certain assumptions about aspirational actions, these actions will look distinctive; but below I'll question whether we need to make the assumptions. First, I'll question Callard's attempt to explain monthsor years-long actions in terms of discrete desires. Second, I'll object to Callard's method of individuating reasons. Third, I'll ask how much the aspirant knows about her goals.

\section{Why try to explain action with isolate desires?}

The agent aims to deepen her grasp of a value that she possesses only inchoately. This is supposed to be one thing that renders aspirational actions distinctive, for Callard claims that deepening one's grasp on a value requires proleptic reasons.

To see why, return to Jane once again. Callard emphasizes that the desire to appreciate music may be quite weak, may need reinforcement with the prospects of chocolate, may need inducements. In part for that reason, we can describe the agent as desiring to desire music more than she currently does. And this, Callard thinks, demands a special account. She writes,

If your activity of music listening is directed at desiring music more than you currently do... then that activity cannot be explained (non-proleptically) by the desire you currently have. For the desire you currently have, considered in abstraction from its aspirational (proleptic) component, would only explain pursuit of the satisfaction of that desire. It cannot explain the deepening or intensification of that desire. (93)

Here, Callard claims that we cannot explain the deepening or intensification of desires without appealing to proleptic reasons. I take it that she means that we can't explain why it would be rational for an agent to try to deepen her desires. After all, desires are fluid: they sometimes deepen, sometimes regress; sometimes intensify, sometimes evaporate. I used to have strong, intense desires to play in sandboxes and, a bit later, to drive fast cars; but those are gone, and others have arisen. But this was just a matter of things happening to me rather than my doing things; I didn't try to bring about these changes, they just occurred. No need to invoke proleptic reasons there. So let's focus on the case of intentionally trying to deepen one's desires. Can intentionally trying to deepen a given desire be explained by that very desire?

I think the answer depends entirely on how much we're willing to take for granted. Here's a case. A long time ago I detested the process of running but wanted to enjoy it. I liked the way in which running long distances gave me opportunities to clear my mind, to be outside, to engage only with what was immediate; I liked the challenges it provided. But I also hated it: there was no moment at which I did not want to stop. I deliberately tried to make myself enjoy it, to desire not just what was incidentally related to running but running itself. And I succeeded. After a while, I came to love the process itself and not just what was contingently connected to it. 
So that's a case in which I intentionally deepened my desire: a mild desire to run, supported almost entirely by features of running which were extraneous to the running itself, was transmuted into a strong desire to run for its own sake. But why is this action supposed to be mysterious, calling out for explanation in terms of proleptic reasons? It's true that to explain the intentional deepening of my desire to run, we have to appeal to other desires (a desire to be outside, to overcome challenges, to clear my mind, etc.). But so what? It's hard to imagine any real case in which only one desire bears on a given action, so we'll always need to consider a set of desires. (In fact, given that there's no uncontroversial standard of individuation for desires, any case that looks like it's explained in terms of one desire can be re-described as a case of explanation in terms of multiple desires. For example, as I eat my lunch am I acting on the desire for salad or a desire for something crunchy and a desire for something satisfying and a desire for something healthy?)

Let me put that question differently: in explaining this action, how much can we take for granted? Here are some facts:

As I ran, running became easier. What was grueling, effortful, and unpleasant became something almost effortless. There's no need to appeal to proleptic reasons in order to explain this feature. We can just note that in the early days, the grueling and unpleasant nature of running counted to some extent against it, whereas in the later days those aspects were gone. So the balance of reasons changed, and we can explain why it changed without appealing to proleptic reasons.

Moreover, as I ran, I began to appreciate features of running that I hadn't formerly noticed. For example, I enjoyed feeling various pains while holding myself to a course of action despite them. I enjoyed having a sense of control over my own fatigue, and ability to bend my actions to my will. So the way in which I understood my activity in the early days differed from the way in which I understood it in the later days. But again, this just means that the balance of reasons in the early days was different than the balance of reasons in the later days. We can explain this without appeal to proleptic reasons.

So let's grant Callard the claim that a desire taken in isolation cannot explain why the agent has reason to deepen that very desire. Still, it's not clear why we would ever want to explain any extended action in terms of isolate desires.

So there's a question about how much we can take for granted. Why can't we just say that in the early days, I had sufficient but not overwhelming reason to engage in running; and then, as time progressed and my skills and abilities and thoughts and preferences changed, I had overwhelming reason to run? The running is rational at each instant; but the factors rendering it rational change, over time, and the reasons counting in favor of it multiply. Just so with the aspiring music student.

\section{The individuation of reasons}

Let me now turn to the aspect of Callard's account that I find most dissatisfying. Callard wants to locate the reason on which the aspirant acts.

Sometimes we do something for more than one reason: I went to the store in order to get milk and for the exercise. Proleptic reasons are double in a more fundamental way. The good music appreciation student is listening to the symphony assigned for her class because music is intrinsically valuable and because she wants a good grade. If she merely cited the first as 
her reason, she would be pretending to a greater love of music than she currently has; if she merely cited the second, she would be incorrectly assimilating herself to the bad student. But her motivational condition is also not one in which she has merely added the first reason to the second, because that situation would describe a music-lover who is (strangely) taking a music appreciation class. The fact that music is intrinsically valuable and the fact that she wants a good grade somehow combine into one reason that motivates her to listen. The reason on which she acts has two faces: a proximate face that reflects the kinds of things that appeal to the person she is now and a distal one that reflects the character and motivation of the person she is trying to be. Her reason is double because she herself is in transition. (7273)

Callard feels the need to say that the agent acts on one reason with two "faces". Let me raise some objections.

First, the idea that agents act on just one reason is controversial enough in simple and immediate cases: when I walk to my office, why can't I be acting on several reasons (enjoying the weather, getting to my destination, etc.)? Moreover, once we consider the months- and years-long actions of becoming an appreciator of music or a doctor or a lover of wisdom, why would anyone be tempted to think that we can locate the reason? What would that even mean? Consider Callard's example of the aspiring doctor, the medical student who "has only a schematic understanding" of what being a doctor involves (35-36). The medical student's days and years are occupied by a variety of tasks: going to classes, reading books, administering shots, talking with colleagues, caring for patients. All of these are in part informed by her overarching goals of becoming a doctor and understanding the value of helping people, but they're also informed by much more particular features: if you want to know why she gives this patient this shot, you need to say much more than that she's trying to become a doctor. So it already seems to me artificial to isolate some years-long action, becoming a doctor, and to look for the reason for which this action is performed. That larger action is made up of an assortment of more particular acts, each of which is informed by multiple reasons.

But suppose we set that aside and grant Callard the claim that the long-term aspirational action should be treated as a singular unit, and that we should look for the reason for which it's done. Callard claims that in the relevant cases, we need to find one reason because the reasons aren't additive. But why should the lack of additivity entail that we need to introduce a distinctive type of reason? There are plenty of cases in which we can say that two reasons that seem contradictory or at least opposed combine into one reason. Take masochism. The masochist wants both pain and pleasure. If you simply said that the masochist wants pain, you'd be incorrectly assimilating him to someone who just seeks pain as such; if you said that he just wants pleasure, you'd be incorrectly assimilating him to someone who just seeks pleasure as such. So the reasons of pain and the reasons of pleasure somehow combine into one reason, a masochistic reason. But there's nothing mysterious about this reason and it doesn't call out for a special account of dual-faced reasons, with one "face" offering pain and the other pleasure. So again, the mere fact that the aspirational acts involve a reason with two aspects that can't be separated doesn't make it distinctive.

Or take a person who seeks challenges in some domain. The skilled athlete wants to play against people who present him with real challenges. So he wants opposition and the possibility of defeat but also wants to win. If you simply said that he wants challenges, you'd be inadvertently assimilating him to someone who just wants life to be difficult, who might satisfy this desire by tying his shoes together or stuffing rocks in his socks. If you simply said that he wants to win, you'd be 
inadvertently assimilating him to someone who would find equal satisfaction in besting children or incompetent opponents. So the reasons of seeking challenges and the reasons of wanting to win somehow combine into one reason, a reason to seek challenging but not unbeatable opponents. But again, there's nothing mysterious about this reason.

So, from the fact that we can't account for the music student's action merely by adding the desire to get good grades to the desire to appreciate music, it doesn't follow that we need to introduce proleptic reasons. For there are many cases in which reasons combine in non-additive ways, with the one reason modulating the other.

\section{Being inarticulate about one's goals}

Above, I've granted Callard the assumption that aspirational activities involve a form of inarticulacy about one's goals. But now I want to push on that assumption. Notice that whether we count the aspiring music student's understanding of the value of music as inchoate depends on our standards for attributing knowledge.

Depending on how much specificity we require, our grasp of any goal or any value can be said to be attenuated or inchoate. Consider a fairly localized action. I get in an argument with a friend. In one sense I know what I'm doing: arguing about who is at fault. In another I don't; there may be hidden motives, jealousies, resentments, compensation for past failures, and all of this may modify the way in which I'm pursuing the goal. Surely the action is intentional, but there's plenty about it that I don't grasp.

Or take a case that more explicitly involves certain values. Take a standard political case. A person advocates for restrictions on immigration and takes himself to be defending his country's status in so doing. But we, looking at this person, see fears, economic anxieties, racism, and so forth. He knows what he's doing but doesn't know all of what he's doing. Again this is a perfectly ordinary case.

What should we say about these cases? The person has a rudimentary awareness of what she's doing and why, but she doesn't possess a deep understanding of her goals. Nonetheless, most accounts of action will treat her as acting intentionally. Take Anscombe's account: it's sufficient, to show that an action is intentional, for the agent to be able to offer some rudimentary conception of what she's doing and why. The conception doesn't need to be deep; it doesn't need to illuminate every aspect of the action; it doesn't need to reveal the action in all its complexity.

Why can't we account for the aspirational cases in the same way? Sure, the music student can't say much about the value of music. But she can say a bit. Minimally, she can say that music seems to her to be of value, though she can't articulate why this is. And she can say that she's trying to become more articulate about why it has value. This is enough to render the action intentional. Or she can point to people she is trying to emulate: she can see that individuals who she respects value music, and she can try to understand why. Certainly that's a perfectly intelligible reason for action. (Incidentally, it's an interesting feature of Callard's examples that all of her cases of aspiration are conventional: they are ones in which the aspiring agent has clear models of what it would be to possess the value. The agent has exemplars from whom she can learn. Callard does not, as far as I can tell, consider any cases in which an individual aspires to appreciate the value of something that no one else values.) 
Callard writes that "The problem posed by large scale transformative pursuits is this: they require us to act on reasons that reflect a grasp of the value we are working so hard and so long to come into contact with, but we can know that value only once we have come in contact with it' (76, emphasis added). But, as the above discussion indicates, the claim that we know the value only at the end of the aspirational process is true only if we have a very demanding account of what constitutes knowledge.

So we can agree with Callard that the aspirant lacks comprehensive, articulate understanding of her goal. But most of our actions share that feature. And I don't think the conclusion should be that most of our actions are aspirational or that they demand some special account of the reasons for which they're done. Standard accounts of action are already constructed in light of the idea that we are not omniscient about our goals.

So here's my final question for Callard: if standard treatments of rational agency allow the agent to be inarticulate about actions which are nonetheless done for reasons, why do aspirational actions raise any distinctive problems?

I've raised several questions about aspiration. I've suggested that aspirational actions look distinctive only when we make several assumptions: (1) that we should explain the rationality of months- or years-long actions in terms of a single desire or goal, without appealing to contingently related desires or goals that would render performance of the action rational; (2) that the non-additive nature of "proleptic" reasons calls out for a special account of dual-faced reasons, whereas the nonadditive nature of many other reasons (those involved in masochism, challenge-seeking, etc.) does not; (3) that the aspiring agent's incomplete understanding of her goal requires a special account, whereas the pervasive forms of incomplete understanding in ordinary cases of action do not.

I reject these assumptions and thus remain unconvinced that aspirational activity raises any distinctive puzzles. Nonetheless, Callard's book is stimulating, nuanced, and well-argued. It deserves great credit for focusing on long-term stretches of activity rather than punctual moments of choice; for emphasizing the way in which central cases of human activity involve striving for a change in one's values; and for rejecting simplistic accounts of these topics. ${ }^{1}$

\footnotetext{
${ }^{1}$ Thanks to Joel von Fossen for helpful comments on this review.
} 